\title{
Female Participation in the Labour Force of Selected Latin American Countries
}

\author{
FARHAT YUSUF and D. K. BRIGGS*
}

\begin{abstract}
Data from 17 Latin American countries concerning female participation in the labour force and selected social, economic and demographic characteristics were examined using the path analysis models. Of the 3 most important independent variables (i. e. those representing female education, fertility and urbanization) the most significant predictor was the proportion of 15-19-year olds receiving secondary education: this accounted for more than two-thirds of the variation in levels of female participation in the labour force.
\end{abstract}

\section{INTRODUCTION}

Latin America, in common with other regions of the Third World, is characterised by low participation rates of females in the labour force. On the average, about one in five Latin American women of working age is economically active [11].

Factors determining the employment of women are extremely complex. At the individual level, a woman's decision on whether or not she will enter or remain in the work force is subject to such factors as financial expediency, availability of acceptable employment, her own education and work skills $[3 ; 16 ; 20]$ and, above all, the expectations and attitudes of her family, society, and her own self, with regard to her "traditional role" as a housewife and mother $[4 ; 24]$.

At a more aggregated national level, it could be hypothesised that the level of female participation in labour force is largely determined by variables, which, in one form or another, are indicative of the economic, social and demographic circumstances obtaining in a country. The purpose of this paper is to test this hypothesis. Data about twenty variables (such as national income per capita, literacy and education levels, fertility and mortality rates, and urbanization) were collated from published sources and analysed in order to investigate the association of these variables with female participation in the labour force of selected Latin American countries.

*The authors are, respectively, Senior Lecturer in Demography, Macquarie University, Sydney, and Lecturer in Educational Administration, Flinders University of South Australia, Adelaide. 


\section{THE DATA}

\section{Sources and Limitations}

This paper is based on data relating to 17 countries of Latin America, each of which had a population of one million or more persons enumerated in the censuses conducted during the 1960s. The four Caribbean countries, namely Cuba, the Dominican Republic, Haiti and Puerto Rico, which qualified for inclusion in the study on the basis of their population size, were excluded because of their socio-cultural and economic diversity from the rest of Latin America.

Although a substantial proportion of the data was taken from international sources such as the United Nations Demographic and Statistical Yearbooks and publications of the International Labour Office $[5 ; 6 ; 11 ; 21$; and 22], two papers written by the staff of the Centro Latino-Americano de Demografia were found to be very useful as data sources.

It may be pointed out that the data for individual countries may be subject to varying degrees of accuracy [8]. Moreover, when making inter-country comparisons, one must realize that a part of the variation in any statistical index could be due to differences in data collection practices and in the operational definitions of the concepts used. For example, women working as unpaid female helpers, particularly in agriculture, are classified differently in different countries: in some they are regarded as economically active and in others they are not $[7 ; 14 ; 15]$.

\section{The Dependent Variables}

Because of the possible conflict between the traditional role of women in the family and their participation in the labour force, we have analysed the participation rates not only for the working ages (assumed to be 15-64 years), but also for the highest reproductive period (20-24 years), the last years of reproduction (40-44 years) and the overall reproductive life span (15-44 years).

For the working age range (15-64 years), the female participation in the labour force varies from about one in eight in Guatemala and Honduras to one in four in Paraguay and Uruguay (Table 1). The average participation rates are 18 percent in Central regions, 19 percent in Tropical regions and 24 percent in Temperate regions of Latin America.

The labour force participation rate is higher for women aged 20-24 than for those aged 40-44 in every country except Nicaragua, where the two age ranges show the same participation rate. In general, women aged 20-24 participate to a greater degree in the labour force than those aged $15-44$ or $15-64$. The inter-regional dif-
Table 1

Some Statistics of Female Participation in Labour Force for Selected Countries of Latin America, around 1960

\begin{tabular}{|c|c|c|c|c|}
\hline \multirow{2}{*}{ Region/Country } & \multicolumn{4}{|c|}{ Labour force participation rates for females aged } \\
\hline & $15-64$ & $15-44$ & $20-24$ & $40-44$ \\
\hline (1) & (2) & (3) & (4) & (5) \\
\hline \multicolumn{5}{|l|}{ CENTRAL } \\
\hline Costa Rica & 17 & 20 & 24 & 17 \\
\hline El Salvador & 18 & 20 & 24 & 18 \\
\hline Guatemala & 13 & 14 & 14 & 13 \\
\hline Honduras & 13 & 15 & 19 & 12 \\
\hline Mexico & 19 & 17 & 23 & 21 \\
\hline Nicaragua & 23 & 22 & 24 & 24 \\
\hline Panama & 24 & 27 & 31 & 27 \\
\hline \multicolumn{5}{|l|}{ TROPICAL } \\
\hline Bolivia & 21 & 22 & 25 & 20 \\
\hline Brazil & 17 & 20 & 23 & 17 \\
\hline Colombia & 20 & 22 & 26 & 20 \\
\hline Ecuador & 17 & 18 & 21 & 17 \\
\hline Peru & $22^{\circ}$ & 24 & 28 & 21 \\
\hline Venezuela & 20 & 22 & 26 & 21 \\
\hline \multicolumn{5}{|l|}{ TEMPERATE } \\
\hline Argentina & 23 & 29 & 40 & 21 \\
\hline Chile & 21 & 26 & 32 & 22 \\
\hline Paraguay & 25 & 27 & 31 & 25 \\
\hline Uruguay & 27 & 33 & 40 & 30 \\
\hline
\end{tabular}

Sources: (1) Information presented in columns 2,4 and 5 for all countries, except Bolivia, was taken from [6]. For Bolivia the relevant information was taken from the reterence listed below.

(2) Information presented in column 3 was taken from [11, Part III]. 
ferences in the labour force participation rates are, however, more pronounced for the age range 20-24 years: in the Temperate region, 36 percent of such females are in the labour force compared to less than 25 percent in the other two regions.

According to the International Labour Office, about a quarter of working females in Latin America are under 20 years of age and 18 percent are 20-24 years old, making a total of about 43 percent under 25 , compared to 41 percent for women in the 25-44 age range [11]. Thus, it appears that the female labour force consists, in about the same proportions, of younger and probably mostly single women and of those who are comparatively older, probably married or living in concensual unions. Since fertility levels in Latin America are high ${ }^{1}$, most of these older women are likely to have borne several children.

\section{The Independent Variables}

Table 2 shows regional averages for each of the twenty independent variables which have been grouped under the following headings: Economic, Occupational, Literacy and Education, Fertility, Mortality, Urbanization, and Other Demographic. ${ }^{2}$

The overall impression given by this table is that the Temperate region is distinctly different from the Central and Tropical regions. It is richer, has a more literate and educated population, is highly urbanized, and is characterised by lower fertility and mortality rates. The Central region has a higher overall per capita income than the Tropical region, but in other respects its situation is less favourable. ${ }^{3}$ This region has a larger percentage of male workers in blue-collar and agricultural occupations and is less urbanized; the population is less literate, with lower levels of education, and has higher fertility and mortality rates. It is necessary to bear in mind, however, the great differences not only between the various countries comprising a region, but also within certain countries. Parts of Brazil, for example, have a degree of industrial development which may unduly influence the figures for the Tropical region as a whole.

\section{ANALYSIS OF THE DATA}

\section{Correlates of Female Participation}

in the Labour Force

Table 3 gives the correlation coefficients between age-specific female participation rates in the labour force and selected economic, demographic and other variables. It is interesting to note that the correlation coefficients calculated for the

${ }^{1}$ Table 2 shows that the total fertility rate in Latin America was about 6 children in the 1960s. 2 .

${ }^{2}$ The regional averages are only given, in order to avoid an unduly lengthy table.

${ }^{3}$ It may. be that this discrepancy is the result of an even less equitable distribution of income in the Central region than in the other regions. labour force participation rates in the working age range (15-64) are, for the majority of variables, statistically not significant at the 5 -percent level. Such correlations as do exist, however, support the traditionally accepted hypothesis that populations which are comparatively richer, with higher literacy and urbanization, but lower fertility and mortality, have a greater proportion of females in the labour force. The low correlations observed may be explained by the fact that the average participation rate for the 15-64 age range obscures the varied susceptibility of working females to social, economic and demographic pressures. The influence of these pressures is clearly shown by the correlation coefficient between the labour force participation rates of 15-44-year old females and other variables; almost half of these coefficients are statistically significant at the 5-percent level. These pressures are even more apparent in the 20-24 age bracket, which is the period in the life of a woman when there is the strongest conflict between her participation in the labour force and her traditional role in the family. As women reach the end of their reproductive lifespan, the demands of their traditional roles become less exacting and consequently their participation in the labour force is less strongly influenced by the various social, economic and demographic factors.

\section{Path Analysis}

The correlation coefficients given in Table 3 under the columns headed "Labour force participation rates for females aged 15-44 (Column 3) and 20-24 (Column 4)", were ranked in the order of magnitude of their absolute values (i.e. irrespective of sign). It was observed that the highest correlation coefficients for each of these age groups were to be found, under the heading of "Literacy and Education", with the variable "Percentage of 15-19-year olds in secondary schools, c. 1965 " ( $\mathrm{r}=0.818$ and 0.869 respectively). The second highest correlations coefficients for each of the above age groups were to be found under the heading of "Fertility", with the variable "Gross reproduction rate, c. $1960 \mathrm{~s}$ " $(\mathrm{r}=-0.776$ and -0.832 respectively). This was followed by the correlation coefficients with other fertility variables ("Crude birth rate, c. 1968" and "Child-woman ratio, c. 1960s" in case of the 20-24 age group and "Crude birth rate, c. 1968" in case of the 15-44 age group). The next highest correlation coefficients were found under the heading "Urbanization" with the variable "Percentage of population in cities of $20,000+$, c. 1970 " ( $r=0.671$ and 0.761 respectively). A further investigation was undertaken, therefore, of the association of these three groups of variables (viz. "Literacy and Education", "Fertility" and "Urbanization") with female participation in the labour force. 
Averages for Selected Characteristics of Latin America and its Regions

Independent Variables

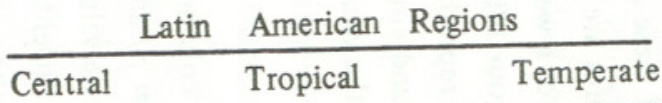

Latin

America

(1)

(2)

(3)

(4)

(5)

ECONOMIC

(1) Per capita income, c. 1970 (in 1960 US\$)

(2) Annual rate of change in per capita income: $1960-1970$

490

440

700

542

OCCUPATIONAL

(3) Percent of male nonagricultural workers in blue collar occupations, c. 1960s

(4) Percent of male nonagricultural workers in white collar occupations, c. 1960s

(5) Percent of male workers in agricultural occupations, c. 1960s

85

12

63

2.3

1.4

\section{LITERACY AND EDUCATION}

(6) Percent literate of population $14+$, c. 1968

61

68

85

69

(7) Percent of 15-19 year olds in secondary schools, c. 1965

(8) Percent literate of female population $15+$, c. 1960 s

40

27

82

61

Table 2-Continued

(4)

(5)

\section{FERTILITY}

(9) Gross reproduction rate, c. $1960 \mathrm{~s}$

(10) Total fertility rate, c. $1960 \mathrm{~s}$

(11) Crude birth rate, c. 1968

(12) Child-woman ratio, c. 1960s

$\begin{array}{cc}3.2 & 3.0 \\ 6.4 & 6.1 \\ 45 & 42 \\ 640 & 651\end{array}$

2.1
4.3
31
521

2.9

\section{MORTALITY}

(13) Life expectancy at birth, c. 1965-1969

$\begin{array}{rrrr}56 & 57 & 64 & 59 \\ 15 & 10 & 7 & 11 \\ 12 & 12 & 10 & 11 \\ 57 & 67 & 56 & 60\end{array}$

(15) Crude death rate, c. late 1960 s

(16) Infant mortality rate, c. late $1960 \mathrm{~s}$

\section{URBANIZATION}

(17) Percent of population in cities of $20,000+$, c. 1970

(18) Percent change in the population in cities of 20,000+ : 1950-1970

\section{OTHER DEMOGRAPHIC}

(19) Annual rate of population growth:

(20) Dependency ratio, c. late $1960 \mathrm{~s}$ 
Independent Variables
Labour force participation rates for females aged

\begin{tabular}{llll}
\hline $15-64$ & $15-44$ & $20-24$ & $40-44$
\end{tabular}

\section{(1)}

(2)

.379

$-.147$

Annual rate of change in per capita

income: $1960-1970$

\section{OCCUPATIONAL}

Percent of male nonagricultural workers in blue collar occupations, c. 1960s

Percent of male nonagricultural workers in white collar occupations, c. 1960s

Percent of male workers in agricultural occupations, c. 1960 s

\section{LITERACY AND EDUCATION}

Percent literate of population 14+, c. 1968

Percent of 15-19 year olds in secondary schools, c. 1965

Percent literate of female population $15+$, c. 1960 s

\section{ECONOMIC}

(3)

(4)

(5)

$\begin{array}{rrrr}-.398 & -.538 & -.533 & -.431 \\ .438 & .501 & .514 & .488 \\ -.461 & -.658^{*} & -.717^{*} & -.461 \\ .463 & .597 & .697^{*} & .491 \\ .627^{*} & .818^{*} & .869^{*} & .618^{*} \\ .489 & .658^{*} & .741^{*} & .510\end{array}$

Continued -

(3)

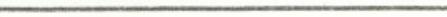


The path analysis approach was used as it could throw light not only on the direct effect of the three groups of independent variables on female participation in the labour force but also on their indirect effects [12]. For the purposes of path analysis, one variable was selected from each of the three groups; the variables selected were the ones which, within the selected group, had the highest correlation with female participation in the labour force. ${ }^{4}$

Because of the very high correlation $(r=0.964)$ between the labour force participation rates of females aged 15-44 and those of females aged 20-24, the computations were performed for one of these age groups only. The age group 15-44 was selected because the incidence of labour force participation in it would not be affected by variations in the age patterns of childbearing as would be the case for the $20-24$ age group.

Although the highest correlation coefficient appeared with the education variable "Percentage of 15-19 year olds in secondary schools, c. 1965" (SEC), and the second highest with the fertility variable "Gross reproduction rate, c. 1960s" (GRR), nevertheless for the purposes of the path analysis, these two variables were placed after the variables of urbanization, "Percentage of population in cities of $20,000+$, c. 1970 " (URB). It was postulated that while, as a general rule, urbanization had a direct influence on fertility and education, the reverse influence of these variables on urbanization was insignificant.

Fig. 1 shows the path analysis model. The arrows indicate the direction of influence exercised by one variable on another. The order of magnitude of the influence of each respective variable is indicated by the value of path coefficients written on the appropriate arrow. The predictive model is given by the following equation:

$$
\mathrm{Y}=-0.193 \mathrm{URB}+0.722 \mathrm{SEC}-0.295 \mathrm{GRR}
$$

where $\mathrm{Y}$ stands for the labour force participation rate for females aged $15-44$, and URB, SEC and GRR are as defined previously. It may be pointed out that the above model explains 69 percent of the variance in the dependent variable.

An interesting feature of this model is that, contrary to expectation, the influence of urbanization on female participation in the labour force, while so slight as to be insignificant, is nevertheless negative. ${ }^{5}$ Further analysis revealed that although the total effect of urbanization, as indicated by the correlation coefficient of

${ }^{4}$ Thus, although more than one "Fertility" variable ranked higher than the selected "Urbation "c. 1960s" which had the highest absolute value of correlation coefficient within the "Fertility" group, was selected.

5 This is indicative of the possibility that rural to urban migration in Latin America perhaps results in women being deprived of employment opportunities.
0.671 between the variables $\mathrm{Y}$ and URB, was substantial, this effect, when decomposed, resulted in the following:

$\begin{array}{lll}\text { Total effect of URB } & = & 0.671 \\ \text { Direct effect } & = & -0.193 \\ \text { Indirect effect } & & \\ \quad \text { through SEC } & & 0.619 \\ \quad \text { through GRR } & = & 0.077 \\ \quad \text { through SEC and GRR } & = & 0.168\end{array}$

It was clear from the above analysis that a major part of the influence exerted by the urbanization variable was indirect, and that it operated through the education and fertility variables.

The path analysis model shown in equation (1) was therefore revised by excluding the urbanization variable (see Fig. 2). The new model is given by the following equation:

$$
\mathrm{Y}=0.613 \mathrm{SEC}-0.232 \mathrm{GRR}
$$

It may be noted that the loss in the amount of variance explained by this model was only one percentage point compared to that in the previous model, i.e. 68 percent compared to 69 percent. Thus it appears that, of the independent variables examined, the two most important predictors of female participation in the labour force are exposure to secondary education and the level of fertility prevalent in a population.

\section{DISCUSSION AND CONCLUSION}

Of the two main predictors of female participation in the labour force which emerged from the path analysis, the more significant was the proportion of $15-19$. year olds receiving secondary education.

One interpretation of this finding may be that the women who receive secondary education are the ones who swell the labour force. ${ }^{6}$ Given the social and cultural attitudes which tend to discourage Latin American women from advancing in a career, it is likely that a woman without adequate education would have limited opportunities for employment in the modern sector of the economy [13]. It may also be noted that a substantial proportion of secondary schools in Latin America can be classified as vocational in that they are designated "commercial", "technical"

${ }^{6}$ Although the figures for secondary education used in this paper did not differentiate between male and female secondary students, a study published in 1974, involving six Latin American countries, showed that almost half of the secondary school enrolments, and 28 percent of enrolments in higher education, were female [24]. 


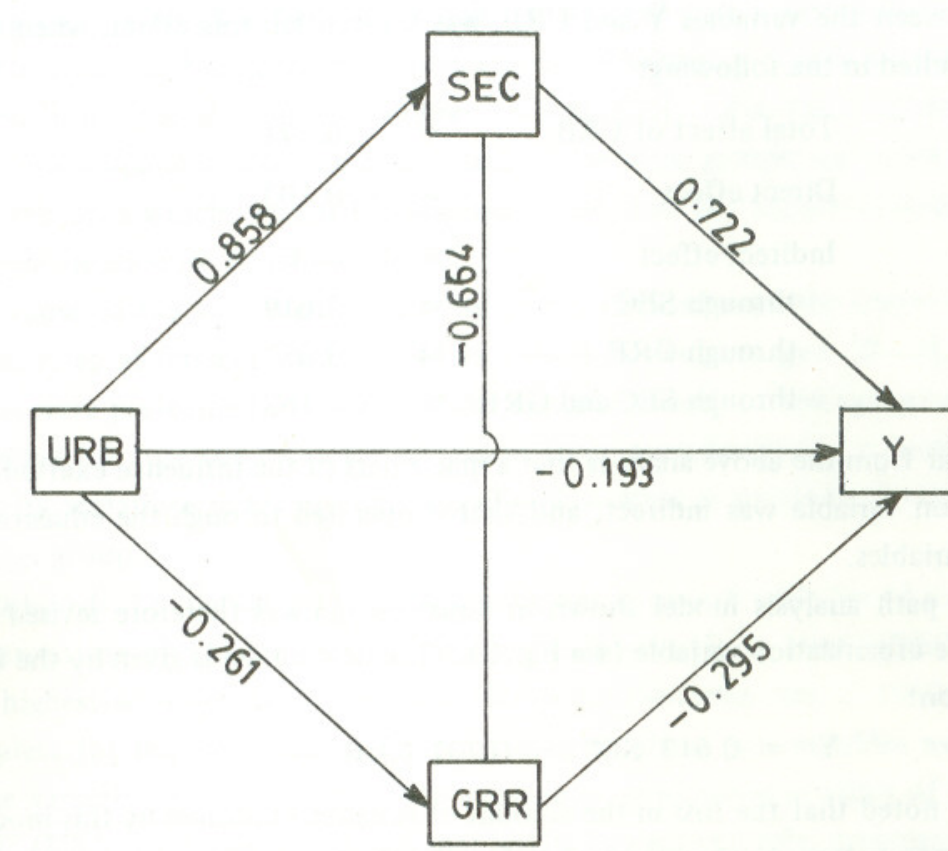

Fig. 1. Path Analysis Model Involving Three Independent Variables.

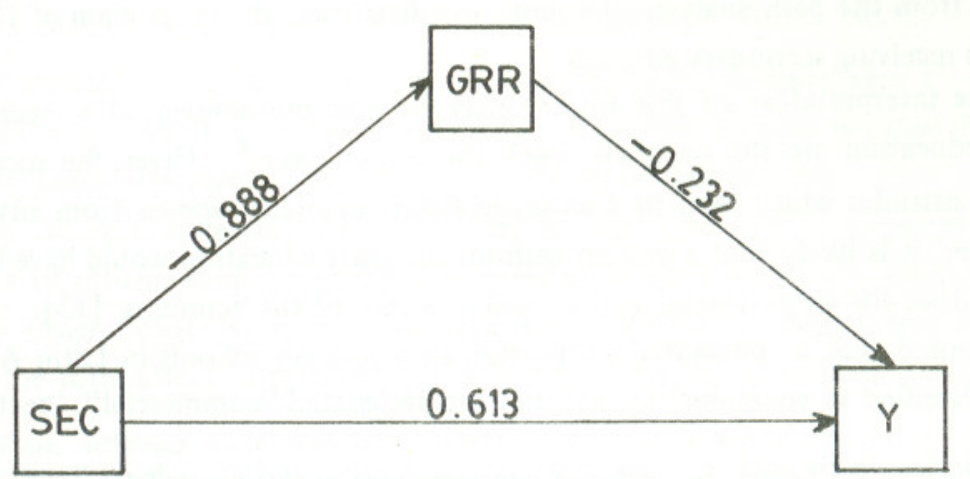

Fig. 2. Path Analysis Model Involving Two Independent Variables. or "normal" (i.e. for prospective teachers). A study published in 1964 of youth and work in Latin America, however, showed that the amount of vocational training given to women was not an indication of their contribution to the economy [10]. Such training is often dysfunctional because of a failure to relate it to employment opportunities in the modern industrial sector. Moreover, the so-called "vocational" training, together with the tertiary-level professional training, is often seen as a means of enabling women to contribute to the culture of the family and society rather than as a preparation for gainful employment [13] .

A second interpretation of the analysis is also based on the evidence that the social and cultural values which predominate in Latin America constitute a major inhibitor of female participation in the labour force [24]. To the extent that exposure to secondary education constitutes exposure to "modern" ways of thought, it may be expected to modify the attitudes of both males and females. Since women's entry into the work force is to a great extent influenced by men, either as heads of families or as employers, it is the effect of education on male attitudes which may facilitate female participation in the labour force.

With regard to the negative association between fertility and female participation in the labour force, it has been postulated here that fertility is the causal factor. It is acknowledged that this view is by no means universally accepted [17]. Those who adopt it argue that, when women have children, they are traditionally required to give priority to their role as mother. Since work structures tend to be too inflexible to accommodate the demands involved in caring for young children, those women who have children find it very difficult to continue in outside employment, and so their work aspirations may be subordinated to their fertility $[3 ; 20]$. Another view is that women's continuance in the labour force negatively affects their fertility. A rise in the costs of childbearing, and in the opportunity costs for mothers, with a decrease in the value of child labour, may persuade women to reduce their fertility, thus freeing themselves to work outside the home. They may be encouraged to do this by finding expanded work opportunities which provide an income as well as a personal status which does not depend on motherhood $[1 ; 18 ; 19]$. A third opinion is that both fertility and labour force participation result from other factors and that therefore their direct relationship may be spurious [23].

In the two models presented in the previous section, the path coefficients for the direct effect of fertility (GRR) on female participation in the labour force were much lower than those of education (SEC) on labour force participation. Moreover, the models also show that education exerts a strong negative influence on fertility. The relationship between fertility and female participation in the labour force 
is thus regarded by the investigators as less important than that between the latter and education, since, as the analysis indicates, it is with the education variable that the more significant effects are observed.

It would appear that whether an increase in women's employment outside the home is desired, or whether a reduction in fertility is sought, a major requirement is to enable more people to benefit from secondary education at least. Not only may the contribution of women to economic development be potentially valuable [2], there is also some evidence that it may also be socially desirable in that it helps to discourage the employment of very young children [9]. Although not all Latin American governments are committed to a policy of limiting population growth, a rapidly increasing population will, however, have significant implications for their efforts to raise the living standards of the masses through social and economic development. The provision of increased educational opportunities is, therefore, one of the major questions to which the social and economic planners in Latin America (and other developing regions of the world) need to address themselves.

\section{REFERENCES}

1. Becker, G. S. An Economic Approach to Human Behavior. Chicago: University of Chicago Press. 1976.

2. Boserup, E. Women's Role in Economic Development. London : Allen and Unwin. 1970.

3. Bowen, W. G., and T. A. Finegan. The Economics of Labor Force Participation. Princeton : Princeton University Press. 1969.

4. Collver, A., and E. Langlois. "The Female Labor Force in Metropolitan Areas : An International Comparison". Economic Development and Cultural Change. 10(4). 1962. pp. 367-385.

5. Conning, A. M. "Latin American Fertility Trends and Influencing Factors". Proceedings of the International Population Conference. Vol. 2. Liege : International Union for the Scientific Study of Population. 1973. pp. $125-148$.

6. Elizaga, J. C. "Demographic Aspects of Women's Labour Force in Latin America and Chile". Proceedings of the International Population Conference. Vol. 3. London : International Union for the Scientific Study of Population. 1969. pp. $1589-1600$.

7. Hartman, M. "Typology of Countries by Labor Force Participation Patterns". Economic Development and Cultural Change. 25(2). 1977. pp. 349-362.
8. Heer, D. M., and E. S. Turner. "Areal Differences in Latin American Fertility". Population Studies. 18(3). 1965. pp. 279-292.

9. International Labour Office. "Youth and Work in Latin America, I : The Employment of Children". International Labour Review. 90(1). 1964. pp. $1-23$.

10. International Labour Office. "Youth and Work in Latin America, II : Youth Employment Prospects”. International Labour Review. 90(2). 1964. pp. 150-179.

11. International Labour Office. Labour Force Projections : 1965-1985. Geneva: International Labour Office Publications. 1971.

12. Kendall, M. G., and C. A. O' Muircheartaigh. Path Analysis and Model Building. London: World Fertility Survey. 1977. (Technical Bulletin)

13. Kirsch, M. "Employment and the Utilization of Human Resources in Latin America". Economic Bulletin of Latin America. 18(1,2). 1973. pp. 60-67.

14. Lopes, V. F. "Problems Affecting the Production of Demographic Data in Latin America”. Proceedings of the International Population Conference. Vol. 1. Liege: International Union for the Scientific Study of Population. 1971. pp. $325-333$.

15. Lopes, V. F. "The Traditional Sources of Demographic Data in Latin America". Proceedings of the International Population Conference. . Vol. 2. Liege : International Union for the Scientific Study of Population. 1973. pp. $355-366$.

16. Mincer, J. "Labor Force Participation of Married Women: A Study of Labor Supply". In National Bureau of Economic Research, Aspects of Labor Economics. Princeton: Princeton University Press. 1962.

17. Smith-Lovin, L., and A. R. Tickamyer. "Labor Force Participation, Fertility Behavior and Sex Role Attitudes”. American Sociological Review. 43(4). 1978. pp. $541-557$.

18. Stolzenberg, R., and L. Waite. "Age, Fertility Expectations and Employment Plans”. American Sociological Review. 42(5). 1977. pp. 769-783.

19. Stycos, J. M., and R. H. Weller. "Female Working Roles and Fertility". Demography. 4(1). 1967. pp. 210-217.

20. Sweet, J. A. Women in the Labor Force. New York: Seminar Press. 1973.

21. United Nations. Demographic Yearbook. New York. (Various years)

22. United Nations. Statistical Yearbook. New York. (Various years)

23. Waite, L. J., and R. M. Stolzenberg. "Intended Childbearing and Labor Force Participation of Young Women: Insights from Non-recursive Models". American Sociological Review. 41(2). 1976. pp. 235-251.

24. Youssef, N. H. Women and Work in Developing Countries. Berkeley: University of California, Institute of International Studies. 1974. 